\title{
Experiences and Needs of Sexual and Gender Minority Young Adults with a History of Suicidal Ideation Regarding Formal and Informal Mental Healthcare
}

\author{
Jennifer de Lange ${ }^{1}$ (1) $\cdot$ Diana D. van Bergen ${ }^{1} \cdot$ Laura Baams $^{1} \cdot$ Margaretha C. Timmerman $^{1} \cdot$ Henny M. W. Bos ${ }^{2}$
}

Accepted: 7 October 2021 / Published online: 16 October 2021

(c) The Author(s) 2021

\begin{abstract}
Introduction Little is known about whether sexual and gender minority (SGM) youth and young adults with suicidal ideation receive adequate mental healthcare in the Netherlands. The aim of this study was to examine healthcare experiences and needs of SGM young adults and how formal and informal mental healthcare can be improved to support SGM youth with suicidal ideation.

Methods In 2018 and 2019, qualitative interviews were conducted among (1) SGM young adults with a history of suicidal ideation ( $n=23$, age 18 to 35), (2) parents of SGM youth with suicidal ideation $(n=16)$, and (3) professionals and volunteers who work with SGM youth $(n=14)$. Thematic analysis was used for coding and analyzing the interviews.

Results Analyses yielded several themes for all groups of participants. Similar themes related to addressing suicidal ideation and SGM issues were found across the three participant groups. Participants perceived a lack of knowledge among professionals regarding SGM issues and perceived that suicidal ideation was sometimes inadequately addressed. Participants expressed the need for training and information on addressing SGM issues and suicidal ideation for parents and professionals. Conclusions Formal mental healthcare is not yet affirmative of SGM identities. Informal and formal healthcare should be improved to address sexual orientation, gender identity, and suicidal ideation.

Policy Implications Findings underpin the need for improving skills and knowledge of mental healthcare professionals to better support SGM youth with suicidal ideation. Parents would benefit from accessible information on SGM-related themes and suicidal ideation.
\end{abstract}

Keywords SGM youth $\cdot$ Suicidal ideation $\cdot$ Healthcare needs $\cdot$ Informal support

\section{Introduction}

Sexual and gender minority (SGM) youth in the Netherlands and comparative countries are at higher risk for suicidal ideation compared to heterosexual and cisgender youth (Kuyper, 2015; Perez-Brumer et al., 2017; Plöderl \& Tremblay, 2015). Although lesbian, gay, and bisexual (LGB) youth report seeking help from mental health providers more often than

Jennifer de Lange

jennifer.de.lange@rug.nl

1 Department of Pedagogical and Educational Sciences, University of Groningen, Grote Rozenstraat 38, 9712TJ Groningen, Netherlands

2 Department of Child Development and Education, University of Amsterdam, Nieuwe Achtergracht 127, 1018WS Amsterdam, Netherlands heterosexual youth (Baams et al., 2018; Lucassen et al., 2011), SGM youth report healthcare is not inclusive of SGM youth (Laiti et al., 2019). Whether SGM youth with suicidal ideation in the Netherlands receive the mental healthcare they seek and need is currently unknown. To successfully prevent or treat suicidal ideation among SGM youth, we need to learn from youth themselves as well as their families, healthcare professionals and volunteers, and what promising leads for formal and informal mental healthcare might be. Therefore, the aim of the current study is to explore experiences and needs related to formal and informal mental healthcare for SGM youth who experience suicidal ideation. In this study, formal healthcare indicates mental healthcare and social work services provided by professionals, and informal healthcare indicates social support from, for example, parents, family, or peers. We will address this aim by examining it in three groups: (1) SGM young adults with a history of suicidal ideation, (2) parents of SGM youth who 
had suicidal ideation, and (3) professionals and volunteers who work with SGM youth with suicidal ideation.

\section{Mental Health Disparities Among SGM Youth and the Role of Family}

Disparities in mental health between SGM and heterosexual, cisgender individuals are to a large extent explained by the experience of gender and sexual minority stress, as outlined in the minority stress framework (Meyer, 2003) and extensions (Hatzenbuehler, 2009; Testa et al., 2015). Notions from the minority stress framework are supported by research showing associations between minority stressors and suicidality (Burton et al., 2013; Hatchel et al., 2019b; Mustanski \& Liu, 2013; Perez-Brumer et al., 2017). For example, Burton et al. (2013) showed that LGB youth reported higher levels of suicidal ideation than heterosexual youth, and this was partly explained by LGB-related victimization, and in a study among transgender adolescents, level of suicidal ideation was partly explained by in-school victimization (Perez-Brumer et al., 2017). A study conducted in the Netherlands also demonstrated an association between LGB-related victimization and suicidal ideation among LGB adolescents (Van Bergen et al., 2013). In addition, negative responses by family or parents to youth's sexual orientation or gender identity such as rejection, non-affirmation, and verbal or physical abuse are important risk factors for developing suicidal ideation (Grossman \& D'Augelli, 2007; Ryan et al., 2009).

The minority stress framework and its extensions emphasize the importance of protective factors, such as social support from family, friends, and community (Hatzenbuehler, 2009; Meyer, 2003; Testa et al., 2015). Previous studies have shown that family, friends, and peers are important sources of social support for SGM youth (McConnell et al., 2016; Parra et al., 2018; Poštuvan et al., 2019; Shilo \& Savaya, 2011; Watson et al., 2019). Support from parents, caregivers, and family can protect SGM youth from developing mental health problems, for example, by affirming and accepting youth's sexual and gender identities (Espelage et al., 2008; Ryan et al., 2010; Simons et al., 2013). In addition, parental connectedness can protect against suicidal ideation (Taliaferro \& Muehlenkamp, 2017).

However, little research has been conducted on parents' needs in supporting their SGM child. In a qualitative study among transgender youth and their caregivers, caregivers expressed their need for support during their child's transitioning process (Schimmel-Bristow et al., 2018). And, to our knowledge, there are no studies that specifically examined parents' needs in supporting an SGM child who is struggling with suicidal ideation.

\section{SGM Youth's Formal Mental Healthcare Usage and Experiences}

There is little research on SGM youth's usage of and experiences with mental healthcare, particularly for SGM youth with suicidal ideation. Studies among SGM youth showed that SGM youth found it difficult to ask for help when experiencing mental health problems (McDermott et al., 2018) and SGM youth did not seek help at all or went to friends for help and less often went to a healthcare professional for help (Lytle et al., 2018). Moreover, a study on lesbian, gay, bisexual, transgender, and questioning (LGBTQ) adolescents' help-seeking beliefs found that LGBTQ adolescents who reported a higher level of help-seeking beliefs reported less suicidal behavior (Hatchel et al., 2019a). This underlines the importance of SGM youth's beliefs about the helpfulness of professional healthcare in reducing mental health problems. However, research on healthcare experiences indicates that mental and physical healthcare do not always fulfill SGM youth's needs and that healthcare is not always perceived as helpful (Fuzzell et al., 2016; Gridley et al., 2016; Meckler et al., 2006). For example, some LGB youth did not disclose their sexual orientation to their physician for confidentiality concerns (Meckler et al., 2006) or because a healthcare provider did not ask about it (Meckler et al., 2006; Rossman et al., 2017). Similar to these findings, a systematic review on disclosure of sexual orientation in healthcare demonstrated that barriers for disclosure were, for example, use of non-inclusive language by a healthcare provider and fear of discrimination, adverse reactions, or a breach of confidentiality by a healthcare provider after disclosure (Brooks et al., 2018).

In addition, some LGBTQ youth had distressing and negative experiences with healthcare providers (Goldberg et al., 2019; Gridley et al., 2016; Snyder et al., 2017). They experienced, for example, poor communication and disrespectful behavior by their physician regarding their LGBTQ identities (Snyder et al., 2017). In addition, transgender youth experienced the use of offensive language and nonaffirmation of their gender identity by pediatric and other healthcare providers (Goldberg et al., 2019; Gridley et al., 2016), and transgender youth perceived a lack of knowledge and competence in transgender issues by mental health professionals (Goldberg et al., 2019; Schimmel-Bristow et al., 2018). Moreover, findings from a qualitative study revealed that LGBTQ young people expressed a need for training practitioners in SGM issues (Sherriff et al., 2011).

Furthermore, transgender youth might seek both mental healthcare and gender-affirming care (e.g., hormonal or surgical treatment) and as a result have unique needs 
and experiences with both types of care. Some healthcare systems require transgender youth to access mental healthcare before they can start gender-affirming care. In the Netherlands, where the current study was conducted, transgender youth need a referral from their general practitioner for an intake at a gender clinic (VUmc, n.d.). Waiting lists for each step of the treatment are long-the waiting time for an intake appointment at a gender clinic can go up to almost 2 years (Radboudumc, n.d.; VUmc, n.d.). This means that while transgender youth are on a waiting list, they might seek and require mental healthcare elsewhere. This further underlines the need for affirming mental healthcare for transgender youth.

In sum, mental healthcare does not yet seem to fulfill SGM youth's needs. To improve mental health services for SGM youth with suicidal ideation, it is important to gain a deeper understanding of experiences and needs regarding mental healthcare, particularly among those who struggle with suicidal ideation.

\section{Healthcare Professionals' and Volunteers' Experiences in Supporting SGM Youth}

Insights into experiences of mental health professionals and volunteers of LGBTQ organizations in supporting SGM youth with suicidal ideation are essential for optimizing suicide prevention efforts in care and community settings. Insights in experiences and needs may inform mental healthcare services and LGBTQ organizations about what is needed to facilitate mental healthcare professionals and volunteers in adequately supporting SGM youth with suicidal ideation. Few studies focused on mental healthcare professionals' needs regarding working with SGM youth. One study examined mental healthcare professionals' perceptions regarding suicidality in LGBT youth (Hughes et al., 2018). It was found that more than half of the professionals felt that they were competent in working with LGBT youth with emotional distress. However, some professionals indicated that they lacked confidence in talking about LGBT issues, and half of the professionals indicated that they did not have access to skills training regarding LGBT youth with suicidal thoughts (Hughes et al., 2018). Another study demonstrated that master's and doctoral-level counseling students felt competent in their awareness of and knowledge about LGB individuals. However, counseling students felt less competent about their counseling skills, especially when they had never seen an LGB client (Graham et al., 2012). Similar findings were demonstrated in a study among pediatric residents. Almost half of the pediatric residents felt they lacked knowledge of SGM youth's needs to discuss these issues with youth (Zelin et al., 2019).

Moreover, a study conducted in the Netherlands reported that when youth care professionals did not discuss youth's sexual orientation or gender identity, this was because they believed it was "irrelevant for their treatment"; others reported not discussing it because they did not want to make someone feel "uncomfortable" or they did not want to "make being LGBT an issue." Nevertheless, the majority of youth care professionals in this study indicated that they wanted to learn more about sexual and gender diversity (Emmen et al., 2015). In addition, in a qualitative study among practitioners in mental health, education, housing, police, social, and youth services, practitioners expressed a need for training to gain confidence in talking about SGM issues, for example, by using real-life examples (Sherriff et al., 2011).

In sum, professionals lack confidence in talking about SGM issues and wish to improve their skills and knowledge. However, not much is known about the needs of volunteers in supporting SGM youth with suicidal ideation.

\section{Current Study}

The current study aimed to examine how SGM youth and young adults with suicidal ideation can be better supported by formal and informal mental healthcare. First, we examined the formal and informal mental healthcare experiences of SGM young adults with suicidal ideation and identified unmet needs. Second, we examined parents' perceptions on the formal mental healthcare experiences of their SGM child with suicidal ideation. In addition, we examined parents' experiences with managing their child's suicidal ideation and identified unmet needs. Third, we examined the experiences of professionals and volunteers who have worked with SGM youth with suicidal ideation and professionals' own needs for working with SGM youth with suicidal ideation.

By including these three independent groups, we are mindful of multiple sources of both formal and informal mental healthcare that may need to be optimized in order to better support SGM youth with suicidal ideation. In this article, we examine experiences and needs regarding suicidal ideation, sexual orientation, and gender identity in formal and informal mental healthcare.

\section{Method}

\section{Participants}

Three groups of participants were interviewed. The first group consisted of 23 Dutch SGM young adults with a history of suicidal ideation, aged between 18 and 31 years old, except for one 35-year-old participant $(M=24.7, S D=4.2)$. We conducted a pilot interview with a 35-year-old participant, and as we wanted to utilize all the information, we included the 35-year-old participant in our sample. 
As for gender identity, eight participants self-identified as transgender men, two as transgender women, four as nonbinary, five as cisgender women, three as cisgender men, and one participant was unsure about one's gender identity. Regarding sexual orientation, four participants identified as lesbian, one as bisexual, one as bi/lesbian, three as pansexual, five as gay/homosexual, one as gay/a little bisexual, and two as queer. One participant did not want to label his sexual orientation. Finally, four participants described their sexual orientation as attracted to women, and one participant described it as attracted to men. The sample consisted of 20 White participants and three multi-ethnic participants.

The second group consisted of 16 Dutch parents of SGM youth with a history of suicidal ideation. These parents were not the parents of the interviewed young adults. Eleven parents were women and five were men. At the time of the interview, their children were aged between 11 and 22 years old. Five of them described their child's gender identity as transgender women, seven as transgender men, two as cisgender women, and two as cisgender men. Parents described their cisgender child's sexual orientation as lesbian, bisexual, and gay. Transgender children's sexual orientation was not systematically asked for in the interviews.

The third group of participants consisted of professionals and volunteers $(n=14)$ who worked with or were in contact with SGM youth with suicidal ideation. We included a diverse group of professionals and volunteers because we found it essential to learn about perspectives on suicidal ideation of SGM youth from a broad range of care and youth workers. Every professional within social services or mental healthcare could encounter SGM youth, and it is therefore important that they can adequately support SGM youth with suicidal ideation. Moreover, volunteers of LGBT organizations may encounter young people who suffer from suicidal ideation. Participants worked as youth care workers $(n=$ 4 ), social workers $(n=4)$, and public health workers (suicide prevention care, $n=2$, and sexual health nurse, $n=1$ ), and three participants worked as a volunteer in an LGBT community-based organization. Not all professionals were trained to address suicidal ideation.

\section{Procedure}

This study was reviewed and approved by the ethics committee of the Department of Pedagogical and Educational Sciences of the University of Groningen on March 7, 2018. Participants for all three groups were recruited through online advertisements on websites and social media of LGBT organizations and were subsequently directed to a website specifically designed for this research project. All interviews were conducted between June 2018 and July 2019, audiorecorded, and transcribed verbatim. All participants gave informed consent before they participated in the interview.
Semi-structured interviews with SGM young adults were conducted face-to-face by the first author, at a location preferred by the participant. Interviews lasted $51 \mathrm{~min}$ on average. SGM young adults received a 10 -euro voucher for participation. After enrollment, but before making an appointment for an interview, potential SGM participants were asked to complete the Suicidal Ideation Attributes Scale (SIDAS) (Van Spijker et al., 2014). The SIDAS measures current severity of suicidal ideation. A score higher than 20 indicates a high risk of suicidal behavior (Van Spijker et al., 2014). If a potential participant scored above a cut-off score of 20, they could not participate in the study and were encouraged to seek help from a list of resources.

Semi-structured interviews with parents were conducted by an external researcher. These interviews were conducted by telephone and lasted $56 \mathrm{~min}$ on average. Parents received a 10-euro voucher for participation.

Interviews with professionals and volunteers were conducted by two external researchers. Data was collected via two focus groups, each comprised of six participants, and due to scheduling issues, two additional interviews were conducted one-on-one. The focus group interviews lasted $110 \mathrm{~min}$ on average, and the two one-on-one interviews lasted $48 \mathrm{~min}$ on average. Professionals and volunteers received a 20 -euro voucher for participation.

Topic lists were developed by the research team, based on existing literature on suicidal ideation and SGM youth. Two pilot interviews with SGM young adults and two pilot interviews with parents were conducted, upon which a few changes in the topic lists were made. SGM young adults' interviews included questions about gender identity and sexual orientation, development of suicidal ideation, social support, mental healthcare experiences, and mental healthcare needs. Parents' interviews included questions about the development of the child's suicidal ideation, recognizing suicidal ideation, behavior towards the child's suicidal ideation, mental healthcare experiences, and parents' needs. Professional and volunteers' interviews included questions about recognizing suicidal ideation, helpful and unhelpful approaches and experiences, and needs regarding working with SGM youth with suicidal ideation. The topic list for the focus group interviews and the individual interviews was similar.

\section{Data Analysis}

Thematic analysis was used to analyze the interviews (Braun et al., 2019). Thematic analysis is a method for analyzing and identifying patterns in qualitative data (Braun et al., 2019). Using reflexive thematic analysis, we aimed to interpret, understand, and describe participants' experiences and needs. The first author coded all three participant groups' transcripts separately using Atlas.ti 8.4. Transcripts were 
coded with an inductive as well as a deductive approach. Codes were not pre-determined but were derived from the data, the research questions, and the interview topics. The first three coded transcripts from the SGM young adult sample and the first three coded transcripts from the parent sample were discussed with the second coder (second author) before coding all the transcripts; codes were adjusted, deleted, or added. After coding all the interviews, the second coder read and looked at all coded transcripts precisely and gave suggestions for changes and new codes. Again, codes were discussed, changed, deleted, or added.

Themes were derived from patterns throughout interviews, the research questions, and the interview topics. Themes were developed for each participant group separately. First, data were added together on a semantic level, for example, statements about helpful and unhelpful experiences with formal healthcare were added together. Next, within and across these broad categories, themes were developed based on shared experiences from participants. For example, one theme that emerged from data of young adult participants was "professionals' unfamiliarity with the impact of growing up as an SGM individual." Our coding frame distinguished between SGM-related and not specifically SGM-related healthcare experiences and needs. Not specifically SGM-related healthcare experiences included, for example, no "click" with a therapist or the perception that their therapists only focused on a psychiatric diagnosis. As a result of our focus in this paper, mainly SGM-related and suicidality-related experiences and needs are discussed.

\section{Results}

\section{SGM Young Adults}

Results of the 23 SGM young adults' interviews are presented in two sections: formal mental healthcare and informal mental healthcare. Four themes regarding formal mental healthcare were identified: (1) addressing suicidal ideation, (2) professionals' unfamiliarity with the impact of growing up as an SGM individual, (3) knowledge about transgender identities, and (4) general counseling skills. Two themes were identified regarding informal mental healthcare: (1) sharing suicidal thoughts and (2) perceived support. See Table 1 for a summary of SGM young adults' results.

Across all interviews, young adults reported various minority stressors that played a role in the development of their suicidal ideation. Minority stressors included loneliness and expecting a bleak future as an SGM adult, struggling with self-acceptance, and having a body that did not align with their gender identity. Young adults also reported various general stressors, such as relationship issues with parents, mental health problems, and school problems. In addition, the age of onset and duration of suicidal ideation varied among participants. Suicidal ideation started between age 14 and age 21 for the majority of the participants $(n=$ 14) and between ages 7 and 12 for seven participants. The period in which participants had suicidal ideation lasted several years. Ten participants had made a suicide attempt. Furthermore, 16 participants mentioned that during the period in which they had suicidal ideation, they experienced difficulties or delays in their studies, or they could not fully participate in their studies or work.

\section{Formal Mental Healthcare}

Most young adults received mental healthcare from more than one professional (e.g., psychologists, psychiatrists, coaches, and social workers). Not all healthcare was focused on young adults' suicidal ideation but was also aimed at coping with depression, $\mathrm{AD}(\mathrm{H}) \mathrm{D}$, or bipolar disorder. Almost all transgender young adults received transgender-specific healthcare (e.g., in a hospital gender clinic).

\section{Addressing Suicidal Ideation by Mental Health Professionals}

SGM young adults who mentioned their suicidal thoughts to the professional had different experiences with how the professional approached suicidal thoughts. Some young adults $(n=8)$ mentioned these thoughts were not addressed adequately or were not taken seriously by the professional. As one participant (unsure about their gender identity, gay, age 18) illustrated: "It was immediately somewhat trivialized, they [the professional] said something like 'everyone that age experiences these kinds of thoughts', 'you will grow out of it', and 'everyone feels hopeless sometimes'."

In addition, one non-binary participant (attracted to men, age 26) and one cisgender woman (lesbian, age 29) mentioned that they were satisfied with how suicidal ideation was discussed by the professional. They mentioned that, for example, the professional normalized the presence of suicidal thoughts and took time to find out where these thoughts came from or helped the participant to improve their social network to overcome feelings of loneliness. Furthermore, when talking about needs, participants indicated that providing room to talk about suicidal thoughts was important and that it would be helpful if a professional would let someone know that there are also other people experiencing suicidal ideation.

\section{Professionals' Unfamiliarity with the Impact of Growing up as an SGM Individual}

Young adults perceived a lack of knowledge among mental health professionals about the impact of growing up as an 
Table 1 Summary of themes

Theme Summary

SGM young adults

Formal mental healthcare Addressing suicidal ideation by mental health
professionals

Professionals' unfamiliarity with the impact of growing up as an SGM individual

Professionals' knowledge about transgender identities

Professionals' general counseling skills

Informal mental healthcare

Sharing suicidal thoughts

Perceived support

Parents of SGM youth

Mental healthcare experiences

Addressing suicidal ideation by mental health professionals

Unfamiliarity with and lack of knowledge of SGM individuals

Support from LGBT organizations and SGM peers

Parents' own experiences and Recognizing suicidal ideation

needs

Talking about suicidal ideation and mental health

Professionals and volunteers

Recognizing and addressing suicidal ideation

Training in sexual and gender diversity

Addressing sexual orientation or gender identity
SI is at times inadequately addressed by professionals

SGM YA perceived professionals were unfamiliar with what it is like growing up as an SGM individual

YA perceived that professionals did not know what being transgender entails

Professionals helped in investigating YAs' thoughts and feelings. This was helpful in managing issues regarding $\mathrm{SO}$ and GI

SI was mostly shared with friends. Some YA only shared it after the period during which they were having SI. Various reactions were received upon disclosure

YA perceived support from friends and parents. Contact with SGM individuals who faced similar challenges was important

A safety plan was set up by the healthcare professionals in collaboration with the child, and this was perceived as helpful for the child

Parents perceived a lack of knowledge among professionals about SGM individuals and in particular about transgender identities. As a result, the healthcare received did not fulfill the child's needs

Parents and children received helpful support from LGBT organizations

Parents saw various signs of SI in their children: social withdrawal, unhappiness, self-harm

Parents were unsure about how to talk about SI with their child and if they did it adequately

Different approaches were utilized in addressing SI. Training is needed on recognizing and addressing SI

Some participants received training in addressing sexual and gender diversity. This was helpful in discussing it with clients

Participants were aware of the use of inclusive language; however, they see that training is needed in organizations

GI gender identity, $L G B T$ lesbian, gay, bisexual, and transgender, $S G M$ sexual and gender minority, $S I$ suicidal ideation, $S O$ sexual orientation, $Y A$ young adults

SGM individual and a lack of adequately addressing this. Some young adults $(n=6)$ said that they had mentioned or hinted at their struggles related to their sexual orientation or gender identity to their professional, but the professional did not go into it or only discussed it superficially. Because participants felt that their sexual and gender identities created challenges in their lives at the time, not adequately addressing these topics was perceived as a missed opportunity for helpful care. For example, one lesbian young adult (cisgender woman, age 29), who had been in a heterosexual relationship, told the professional she was struggling with her sexual orientation. The professional then decided that it was better to work on the participant's depression first before addressing questions regarding sexual orientation, and the professional offered a premature conclusion about the participant's sexuality. As the young adult explained: "She [the professional] said 'you're probably not a lesbian', it would have prevented a lot of pain if she had just stayed with the topic."

In addition, two young adults perceived that their professionals held incorrect assumptions about how their sexual orientation or gender identity mattered in their 
lives. As one lesbian young adult (cisgender woman, age 23) illustrated: "My professional said: 'you are attracted to women, that is normal in this society'," yet this young adult felt that, for her, it was not normal and she did not feel heard. Another participant (cisgender woman, bisexual, age 30) explained how a professional held a preconceived notion about bisexuality: "He [the professional] interpreted it as if I needed a lot of physical contact. That something was wrong with my sex life and he could not help me with that."

When asked what their needs and desires were in terms of mental healthcare, SGM young adults in this study ( $n$ =13) mentioned that they would have appreciated if a professional had asked more questions about sexual orientation and gender identity and had acknowledged that being an SGM individual could have an impact on someone's life. Young adults assumed this would have helped in their gender or sexual orientation identification process and self-acceptance of their identity. In addition, young adults $(n=15)$ mentioned that they would like professionals to know, or be willing to learn, what it is like to grow up as an SGM individual, including intersections with culture and religion, and what relevant resources might be for an SGM young individual.

\section{Professionals' Knowledge About Transgender Identities}

Some participants $(n=7)$ perceived a lack of knowledge among professionals about transgender identities. For example, several transgender young adults mentioned they had to educate their professional about transgender identities. A transgender young adult (transgender man, mostly gay, age 24) illustrated: "What I thought was less good and less pleasant, I perceived that they did not know much about it [being transgender]. You need help yourself...., and at the same time you need to educate your professional about it." However, some young transgender adults $(n=$ 5) mentioned that they had met gender-affirming professionals who used their correct pronouns, were aware of transgender-specific issues, and took their gender identity seriously. A transgender participant (transgender man, pansexual, age 19) explained: "It was so nice being able to share about transgender issues, for example transitioning. She [the professional] understood, and knew what this was about."

In regard to needs, asking relevant and inclusive questions about sexual orientation or gender identity and the issues that may arise was seen as critical by young adults. One non-binary young adult (attracted to men, age 26) stated: "Looking in the mirror could evoke very negative thoughts, and depression. As a professional, you should realize how hard that [looking in the mirror] can be."

\section{Professionals' General Counseling Skills}

Some young adults described some more general counseling skills of professionals which helped them manage issues regarding sexual and gender identity. Several young adults $(n=5)$ mentioned that a professional had motivated them to examine their own feelings, emotions, and thought patterns and supported them in acquiring skills to cope with negative thoughts regarding their sexual orientation and gender identity. Professionals did so by, for example, asking helpful questions about feelings and thoughts, and this encouraged young adults to articulate and express their feelings.

\section{Informal Mental Healthcare}

\section{Sharing Suicidal Thoughts}

All young adults mentioned having shared their suicidal thoughts with at least one person in their environment: friends $(n=13)$, parents $(n=5)$, and a family member or a teacher $(n=7)$. However, some of them had only shared it with the aforementioned sources when they were already receiving professional healthcare or even after the period during which they experienced suicidal thoughts. Reasons for not sharing suicidal thoughts with a person were because disclosure felt, for example, "loaded" and "heavy." As one participant (transgender man, no label for sexual orientation, age 22) described: "I did not want to burden my mother with it [suicidal thoughts] because she would have started worrying a lot." Some young adults were scared to share their suicidal thoughts because they thought that people "were not eager to listen to them" or they feared people's reactions.

Young adults who had shared their suicidal thoughts with someone in their environment received different reactions. One participant (non-binary, lesbian, age 27) recalled that her mother found it "difficult to hear" and thought she [the participant] was "a difficult child." By contrast, other participants felt supported when the person they had shared their suicidal thoughts with listened to them without judgment and was there for them. For example, one participant (non-binary, attracted to men, age 26) who had shared their suicidal thoughts with their sister said: "She reacted on it by saying let us make sure that we stay in touch better and more frequently."

\section{Perceived Support}

Young adults felt supported by friends $(n=16)$, their partner $(n=3)$, family members including parents $(n=9)$, and other persons such as mentors, even if young adults had not disclosed their suicidal thoughts to those persons. As for friends, young adults found it supportive to have someone to confide in and "just be around them." Regarding parents, 
young adults stated that they did not often talk about negative emotions and feelings with them, but knowing their parents cared about them felt supportive. Furthermore, online and in-person contact with SGM individuals who had faced similar challenges was an important source of informal support. One non-binary young adult (attracted to men, age 26) who attended a meeting for transgender youth said: "I saw other transgender persons there for the first time. They had been in their transition process for a long time... Your whole face, everything could look different. That was a type of support I experienced."

\section{Parents of SGM Youth}

Results from the sixteen parent interviews are described in two sections: mental healthcare experiences and parents' own experiences and needs. Three themes regarding mental healthcare experiences were identified: (1) addressing suicidal ideation by mental health professionals, (2) unfamiliarity with and lack of knowledge of SGM individuals, and (3) support from LGBT organizations and SGM peers. Two themes regarding parents' own experiences and needs were identified: (1) recognizing suicidal ideation and (2) talking about suicidal ideation and mental health. See Table 1 for a summary of parents' results.

Overall, parents indicated multiple factors that played a role in their child's suicidal ideation. They mentioned factors related to gender identity and sexual orientation, for example, feeling different, loneliness, worrying about the future, and bullying. Factors unrelated to gender identity or sexual orientation were also indicated, for example, divorced parents.

\section{Formal Mental Healthcare Experiences}

All parents' children had received some sort of mental healthcare, ranging from psychologists, psychiatrists, social workers, coaches, and youth care workers. Eleven children accessed a combination thereof. Mental healthcare was not always focused on suicidal ideation, but also on self-esteem, social anxiety, and depression. Furthermore, all transgender children of parents in the current study received healthcare from a gender clinic. Six parents mentioned waiting lists for gender-affirming care as a problem, varying between 4 and 18 months. Some parents changed to a different gender clinic where they hoped to receive care sooner.

\section{Addressing Suicidal Ideation by Mental Health Professionals}

Some parents were aware that suicidal ideation was discussed in treatment $(n=5)$, and they mentioned experiences that were helpful for the child. First, parents explained how professionals and children had identified signals pointing to the emergence of suicidal ideation and had set up a safety plan for those situations, including beneficial coping techniques. Second, giving room to talk about suicidal thoughts during treatment was perceived by parents to be helpful for the child.

\section{Unfamiliarity with and Lack of Knowledge of SGM Individuals}

Parents mentioned experiences regarding professionals' knowledge and skills in working with SGM individuals. For example, parents $(n=6)$ perceived a lack of knowledge in addressing LGB-related issues, and in particular transgender identities, by professionals. One parent of a transgender son (age 14) explained that a professional focused entirely on gender-related issues: "She [professional] heard the word transgender and was like that is the problem, and only focused on that part. But for our child being transgender was not the problem but being depressed and unhappy was." In contrast, another parent of a transgender son (age 20) mentioned that a professional working with their child did not focus on being transgender at all, while being transgender was important to the child.

Regarding needs, parents wished professionals were trained to effectively address gender identity and sexual orientation-related issues. Five parents of transgender children wished professionals would gain knowledge about what it is like growing up as a transgender person and issues that can arise from that, such as the impact of gender minority stressors. One parent of a transgender son (age 15) explained: "When he discovered being transgender, he told the psychologist about it and he had to explain [to] the psychologist what it entails." Parents also wished professionals would gain more knowledge about how to inquire after and talk about gender identity in healthcare, for example, what questions a professional should or should not ask or to which organizations they can refer to for transgender-specific healthcare.

\section{Support from LGBT Organizations and SGM Peers}

Two parents mentioned that individual support from an organization for transgender persons was helpful for their child, and two parents indicated that meetings with other transgender young persons were important as their children learned about themselves and felt supported in these meetings. Furthermore, parents $(n=7)$ indicated that particularly online and in-person contact with SGM peers was supportive for their child. One parent whose transgender son (age 15) went to a summer camp for transgender youth mentioned that the child "received a lot of recognition and did not need to explain anything." In addition, three 
parents mentioned how family support from a transgenderspecific organization was valuable to them.

\section{Parents' Own Experiences and Needs}

\section{Recognizing Suicidal Ideation}

Parents talked about how they recognized their child was having suicidal thoughts and what signs they received. Few parents $(n=4)$ reported that their child had disclosed their suicidal thoughts to them directly and some parents were told by the child's healthcare professional that their child had thoughts about ending their life. However, all parents saw that their child was experiencing depressive feelings. Parents described that the child self-harmed $(n=$ $7)$, looked depressed $(n=7)$, looked unhappy $(n=4)$, and did not want to go to school anymore or received worse grades than before $(n=8)$. In addition, parents noticed social withdrawal, and they could not get "in touch" with their child $(n=11)$.

\section{Talking About Suicidal Ideation and Mental Health}

Parents had mixed experiences with talking about mental health and suicidal ideation with their child. All parents supported their child, for example, they talked to them about their state of mind, let the child know they were there for them, and tried to make contact with the child. However, some of the parents $(n=4)$ stated that at the time they were not sure whether they were asking the right questions or doing the right thing to get in touch with their child or get their child to open up. One parent of a transgender son (age 14) explained: "But maybe I had to ask questions in a different way, so he would have been triggered to tell something. Now he just could not say anything." Parents who were aware of their child's suicidal thoughts $(n=8)$ asked about it, talked about it with their child, and let their child know they could share their negative feelings. However, parents noticed it was difficult for their child to talk about negative feelings and emotions, such as suicidal thoughts. One parent of a transgender daughter (age 17) explained: "It was really difficult. She felt ashamed [about having suicidal thoughts]. She could not say it. We tried to talk about it, but it was not easy."

When talking about needs regarding supporting their child, parents $(n=11)$ wished they had received support in addressing SGM-related issues and suicidal ideation with their child. In addition, some parents wished that information about being transgender and discussing suicidal ideation would have been made available to them.

\section{Professionals and Volunteers}

Results of two focus group discussions and two individual interviews with professionals and volunteers are described in three themes: (1) recognizing and addressing suicidal ideation, (2) training in sexual and gender diversity, and (3) addressing sexual orientation or gender identity. See Table 1 for a summary of professionals' and volunteers' results. Most participants worked in youth care or social work $(n=8)$, one of them worked specifically with SGM youth, and two of them had expertise in sexuality topics. Three participants worked as volunteers in LGBT-specific organizations, two participants worked in care regarding suicide prevention or aftercare, and one participant worked as a sexual health nurse. Participants had a wide range of experiences in working with SGM youth.

They mentioned various factors as important for the development of suicidal thoughts among SGM youth. For example, they mentioned that most youth experienced a combination of SGM-related issues, such as loneliness, internalized transphobia or homophobia, fear of rejection and actual rejection by family, and other issues such as difficulties in their home environment.

\section{Recognizing and Addressing Suicidal Ideation}

Professionals and volunteers discussed several experiences related to recognizing and addressing suicidal ideation. First, they mentioned various indicators of suicidal ideation, for example, social withdrawal, self-harm, and a somber expression. Moreover, one professional (social work) mentioned that she explicitly asks youth whether they are having suicidal thoughts. Second, professionals also discussed how they addressed suicidal ideation with a client. A professional who works in suicide prevention care mentioned that they ask specific questions about the client's suicidal ideation, such as about the intensity and severity of suicidal thoughts and whether someone has made concrete plans for suicide. In addition, they utilized a crisis safety plan for the client. In this plan, clients describe signs of increasing suicidal ideation and who they can reach out to for help. Mental health professionals in youth care or social work who thought or observed someone was having suicidal thoughts asked questions to assess the severity and then decided whether they had to refer a client to specialized care.

Needs among professionals and volunteers to treat or address the suicidal ideation of SGM clients were also discussed. Professionals thought a standard training about recognizing and addressing suicidal ideation for every professional in youth care or social services was important. A volunteer of an LGBT-specific organization wished she had received training regarding how to address suicidal ideation. 
She explained: "It would have been great if [organization] had offered a training in it [addressing suicidal ideation]. If you come across such a situation, what is the best thing to do?" In addition, she mentioned that it would be valuable if volunteers could consult an experienced professional in suicidal ideation.

\section{Training in Sexual and Gender Diversity}

Professionals mentioned several experiences during which they learned about sexual and gender diversity. First, some professionals in youth care, social work, and suicide prevention care received training in discussing sexuality and gender with youth, using a comprehensive and inclusive approach. For example, one professional (LGBT-specific care) indicated that they learned most from "stories narrated by transgender persons." Another professional (suicide prevention care) received a training from an LGBT organization, and she explained that she learned "dos and don'ts" for interacting with SGM clients. Professionals indicated that this was helpful for them in working with SGM youth.

\section{Addressing Sexual Orientation or Gender Identity}

Professionals brought up how they had developed awareness of the language they use while talking with youth about relationships or sexuality. Professionals in youth care mentioned, for example, the importance of asking non-heteronormative questions such as "are you in a relationship?" However, one professional (social work) also mentioned she sometimes found it difficult to be aware of her language when she works with a transgender client. She explained: "I am trying so hard to not use the wrong pronouns that it almost seems forced when I say it." Yet, when she feels this way, she talks about it openly with the client. Furthermore, professionals found it is important to be nonjudgmental and unbiased or be aware of their own biases and points of view on sexuality and gender.

In addition, professionals provided examples from other professionals to show how transgender youth should not be cared for, including non-inclusive language or lack of familiarity with transgender-related issues. For example, a professional (social work) mentioned: "There was a transgender adolescent who was enrolled in sports education, and the whole team did not know how to deal with the question about which locker room to go to."

Professionals and volunteers articulated several needs and gaps in healthcare for SGM clients with suicidal ideation. First, they would like to have the possibility to contact experienced professionals in the field of sexual orientation and gender identity whom they can consult about SGM clients' cases. For example, a professional (youth care) explained: "That you can discuss a case with someone to check together if you have thought about everything...Someone who is from the community and who is also specialized in it [SGM and suicidal ideation]." Second, they indicated it would be valuable if every professional or volunteer in mental healthcare received basic training in sexual and gender diversity and how to address it.

\section{Discussion}

This study assessed mental healthcare experiences and needs through qualitative interviews with three groups of participants: SGM young adults with a history of suicidal ideation, parents of SGM youth with a history of suicidal ideation, and professionals who worked with SGM youth with suicidal ideation. By interviewing three groups of participants, we intended to bring multiple perspectives together to gain insight into what could be improved in mental healthcare for SGM young adults with suicidal ideation and what role parents could play in supporting their child. Similar experiences were described by parents and young adults, and similar needs were expressed across the three participant groups.

For suicidal ideation, findings revealed that not all young adults had shared their suicidal ideation with their parents or healthcare professional or they felt suicidal ideation had not adequately been addressed. Concurrently, parents at times felt incompetent in addressing suicidal ideation and expressed a need for support in doing so. Previous research showed that educating parents about suicidal ideation increased knowledge and self-efficacy (Torok et al., 2019). Both the findings of Torok et al. (2019) study and the findings of the current study stress the importance of support resources and tools for caregivers to better recognize and address suicidal ideation. Moreover, professionals and volunteers expressed a need for education about recognizing and addressing suicidal ideation. It might be especially important to educate volunteers and professionals of LGBT-specific organizations as they can serve as gatekeepers for suicide prevention. A systematic review on the long-term effects of gatekeeper training on suicide prevention showed knowledge endured over a longer time; however, they also suggest the importance of maintenance of these skills (Holmes et al., 2021).

Consistent with findings in existing research, mental healthcare was not yet meeting the needs of SGM young adults (Fuzzell et al., 2016; Goldberg et al., 2019; Gridley et al., 2016). Both young adults and parents felt that sexual orientation or gender identity had inadequately been addressed in mental healthcare. In line with previous research (Goldberg et al., 2019; Gridley et al., 2016), young adults and parents experienced a lack of knowledge among professionals about transgender identities. Furthermore, findings of this study indicate that young adults had not experienced explicit rejection or disrespectful language from mental healthcare professionals; however, they perceived more subtle 
discrimination. Holding assumptions about SGM individuals' experiences in society, using the wrong pronouns, and nonaffirmation of gender identity are forms of sexual orientation and gender identity microaggressions (Nadal et al., 2010). It is important that professionals are willing to learn about minority stress, but also about the use of inclusive language. Using language that is affirming of gender and sexual diversity ensures that SGM youth feel heard and supported. The importance of understanding the concept of minority stress and using inclusive and affirming language was recognized by professionals, who expressed the need for education about sexual and gender diversity for social workers and mental healthcare professionals.

The findings of this study suggest that youth and young adults might benefit from in-person and online informal support, such as peer support or support groups. In addition, supportive friends may help LGB youth with selfacceptance (Shilo \& Savaya, 2011) and protect against suicidality (McConnell et al., 2015). In this study, consistent with previous research (Schimmel-Bristow et al., 2018), parents expressed a need for (online) support resources or information about gender diversity and transitioning processes. Support resources could take different forms; our study suggests that support groups for parents with a transgender child might be valuable.

\section{Implications for Social Policy and Practice}

The findings of this study give several suggestions for social policy and practice regarding formal and informal healthcare for SGM youth with suicidal ideation in the Netherlands. First, professionals and professionals in training, such as social workers, counselors, and psychologists, should have the possibility to learn within their organization or attend training about sexual and gender diversity, including minority stress, sexual orientation and gender microaggressions, and the use of inclusive language. For example, social studies and institutes that train future mental healthcare professionals need to include sexual and gender diversity as a part of their curricula. In addition, within youth care and mental healthcare organizations, sexual and gender diversity should be included in training programs. For example, organizations that provide mental healthcare for individuals with suicidal thoughts should provide training on inclusive language. Furthermore, the use of inclusive language should be included in organizations' policies. Second, the early identification of (the development of) suicidal ideation is crucial. Therefore, it is important to educate parents, mental healthcare professionals, and volunteers of LGBT organizations into recognizing and addressing suicidal ideation. Within professional healthcare, training on suicidal ideation should be offered in the regular curriculum. In addition, resources and tools on how to support an SGM child with suicidal ideation should be made available for parents and volunteers of LGBT organizations as they can serve as gatekeepers for suicide prevention (Holmes et al., 2021; Torok et al., 2019).

\section{Limitations, Strengths, and Future Research}

The current study had several important limitations. First, there was an underrepresentation of participants of color within all participant groups. Second, the parent sample consisted mainly of parents of transgender children. Specific needs of parents of sexual minority children are somewhat understudied in this article. Third, almost all parents were supportive of the SGM identity of their child. Because of this, parents' findings are not generalizable to all parents. Fourth, even though the group of professionals was diverse in occupations, psychologists or psychiatrists were not included. Regardless of these limitations, since suicide prevention is by definition multifaceted in nature, it is valuable that our study brought together perspectives from three sources, which can be used to improve formal and informal mental healthcare for SGM youth with suicidal ideation.

For future research, it is crucial to better understand the specific needs and experiences of SGM youth of color with suicidal ideation and their parents, as well as the experiences and needs of SGM youth from different ethnic backgrounds and religions. In addition, it is important to gain more insight into the specific needs of psychologists, psychotherapists, and psychiatrists regarding addressing sexual and gender diversity. Finally, it would be valuable to investigate how inclusive and SGM affirmative practice could be implemented and whether this improves mental healthcare for SGM youth.

Acknowledgements We would like to thank René Broekroelofs, Afiah Vijlbrief, Martijn Bool, and everyone who participated in an interview.

Author Contribution All authors contributed to the study conception and design. Material preparation was performed by all authors. Data collection, interpretation, and analysis were performed by Jennifer de Lange. Diana van Bergen checked and supplemented all codes as a second coder and helped with interpretation of the data. Jennifer de Lange wrote the first draft of the manuscript, and all authors commented on previous versions of the manuscript. All authors read and approved the final manuscript.

Funding This research was funded by ZonMw, the Netherlands Organisation for Health Research and Development, project number 531004005 .

Code Availability Codes are available upon request.

\section{Declarations}

Ethics Approval This study was approved by the ethics committee of the Department of Pedagogical and Educational Sciences of the University of Groningen on March 7, 2018.

Consent to Participate All participants gave informed consent before participating in the study. 
Conflict of Interest The authors declare no competing interests.

Open Access This article is licensed under a Creative Commons Attribution 4.0 International License, which permits use, sharing, adaptation, distribution and reproduction in any medium or format, as long as you give appropriate credit to the original author(s) and the source, provide a link to the Creative Commons licence, and indicate if changes were made. The images or other third party material in this article are included in the article's Creative Commons licence, unless indicated otherwise in a credit line to the material. If material is not included in the article's Creative Commons licence and your intended use is not permitted by statutory regulation or exceeds the permitted use, you will need to obtain permission directly from the copyright holder. To view a copy of this licence, visit http://creativecommons.org/licenses/by/4.0/.

\section{References}

Baams, L., De Luca, S. M., \& Brownson, C. (2018). Use of mental health services among college students by sexual orientation. LGBT Health, 5(7), 421-430. https://doi.org/10.1089/lgbt.2017. 0225

Braun, V., Clarke, V., Hayfield, N., \& Terry, G. (2019). Thematic analysis. In P. Liamputtong (Ed.), Handbook of Research Methods in Health Social Sciences, (pp. 843-860). Springer Singapore. https://doi.org/10.1007/978-981-10-5251-4_103

Brooks, H., Llewellyn, C. D., Nadarzynski, T., Pelloso, F. C., De Souza Guilherme, F., Pollard, A., \& Jones, C. J. (2018). Sexual orientation disclosure in health care: A systematic review. British Journal of General Practice, 68(668), e187-e196. https://doi.org/10.3399/ bjgp18X694841

Burton, C. M., Marshal, M. P., Chisolm, D. J., Sucato, G. S., \& Friedman, M. S. (2013). Sexual minority-related victimization as a mediator of mental health disparities in sexual minority youth: A longitudinal analysis. Journal of Youth and Adolescence, 42(3), 394-402. https:// doi.org/10.1007/s10964-012-9901-5

Emmen, M., Felten, H., Addink, A., Bakker, P. P., Boote, M., \& Keuzenkamp, S. (2015). Jong en anders. Onderzoek naar de aandacht voor lesbische, homo, bi-jongeren, transgenderjongeren en jongeren met een intersekse conditie in de jeugdsector. Journal of Social Intervention: Theory and Practice, 24(3), 21-42. https:// doi.org/10.18352/jsi.454

Espelage, D. L., Aragon, S. R., Birkett, M., \& Koenig, B. W. (2008). Homophobic teasing, psychological outcomes, and sexual orientation among high school students: What influence do parents and schools have? School Psychology Review, 37(2), 202-216. https:// doi.org/10.1080/02796015.2008.12087894

Fuzzell, L., Fedesco, H. N., Alexander, S. C., Fortenberry, J. D., \& Shields, C. G. (2016). "I just think that doctors need to ask more questions": Sexual minority and majority adolescents' experiences talking about sexuality with healthcare providers. Patient Education and Counseling, 99(9), 1467-1472. https://doi.org/10.1016/j. pec.2016.06.004

Goldberg, A. E., Kuvalanka, K. A., Budge, S. L., Benz, M. B., \& Smith, J. A. Z. (2019). Health care experiences of transgender binary and nonbinary university students. Counseling Psychologist, 47(1), 59-97. https://doi.org/10.1177/0011000019827568

Graham, S. R., Carney, J. S., \& Kluck, A. S. (2012). Perceived competency in working with LGB clients: Where are we now? Counselor Education \& Supervision, 51(1), 2-16. https://doi.org/10. 1002/j.1556-6978.2012.00001.x

Gridley, S. J., Crouch, J. M., Evans, Y., Eng, W., Antoon, E., Lyapustina, M., Schimmel-Bristow, A., Woodward, J., Dundon, K., Schaff, R., McCarty, C., Ahrens, K., \& Breland, D. J. (2016). Youth and caregiver perspectives on barriers to gender-affirming health care for transgender youth. Journal of Adolescent Health, 59(3), 254261. https://doi.org/10.1016/j.jadohealth.2016.03.017

Grossman, A. H., \& D'Augelli, A. R. (2007). Transgender youth and life-threatening behaviors. Suicide and Life-Threatening Behavior, 37(5), 527-537. https://doi.org/10.1521/suli.2007.37.5.527

Hatchel, T., Ingram, K. M., Mintz, S., Hartley, C., Valido, A., Espelage, D. L., \& Wyman, P. (2019a). Predictors of suicidal ideation and attempts among LGBTQ adolescents: The roles of help-seeking beliefs, peer victimization, depressive symptoms, and drug use. Journal of Child and Family Studies, 28(9), 2443-2455. https:// doi.org/10.1007/s10826-019-01339-2

Hatchel, T., Polanin, J. R., \& Espelage, D. L. (2019b). Suicidal thoughts and behaviors among LGBTQ youth: Meta-analyses and a systematic review. Archives of Suicide Research, 25(1), 1-37. https://doi.org/10.1080/13811118.2019.1663329

Hatzenbuehler, M. L. (2009). How does sexual minority stigma get under the skin? A psychological mediation framework. Psychological Bulletin, 135(5), 707-730. https://doi.org/10.1037/a0016441

Holmes, G., Clacy, A., Hermens, D. F., \& Lagopoulos, J. (2021). The long-term efficacy of suicide prevention gatekeeper training: A systematic review. Archives of Suicide Research, 25(2), 177-207. https://doi.org/10.1080/13811118.2019.1690608

Hughes, E., Rawlings, V., \& McDermott, E. (2018). Mental health staff perceptions and practice regarding self-harm, suicidality and helpseeking in LGBTQ youth: Findings from a cross-sectional survey in the UK. Issues in Mental Health Nursing, 39(1), 30-36. https:// doi.org/10.1080/01612840.2017.1398284

Kuyper, L. (2015). Jongeren en seksuele oriëntatie. Ervaringen van en opvattingen over homoseksuele, biseksuele en heteroseksuelejongeren. Den Haag: Sociaal en Cultureel Planbureau

Laiti, M., Pakarinen, A., Parisod, H., Salanterä, S., \& Sariola, S. (2019). Encountering sexual and gender minority youth in healthcare: An integrative review. Primary Health Care Research and Development, 20(e30), 1-13. https://doi.org/10.1017/S146342361900001X

Lucassen, M. F. G., Merry, S. N., Robinson, E. M., Denny, S., Clark, T., Ameratunga, S., Crengle, S., \& Rossen, F. V. (2011). Sexual attraction, depression, self-harm, suicidality and help-seeking behaviour in New Zealand secondary school students. Australian and New Zealand Journal of Psychiatry, 45(5), 376-383. https:// doi.org/10.3109/00048674.2011.559635

Lytle, M. C., Silenzio, V. M. B., Homan, C. M., Schneider, P., \& Caine, E. D. (2018). Suicidal and help-seeking behaviors among youth in an online lesbian, gay, bisexual, transgender, queer, and questioning social network. Journal of Homosexuality, 65(13), 1916-1933. https://doi.org/10.1080/00918369.2017.1391552

McConnell, E. A., Birkett, M. A., \& Mustanski, B. (2015). Typologies of social support and associations with mental health outcomes among LGBT youth. LGBT Health, 2(1), 55-61. https://doi.org/ 10.1089/lgbt.2014.0051

McConnell, E. A., Birkett, M., \& Mustanski, B. (2016). Families matter: Social support and mental health trajectories among lesbian, gay, bisexual, and transgender youth. Journal of Adolescent Health, 59(6), 674-680. https://doi.org/10.1016/j.jadohealth.2016.07.026

McDermott, E., Hughes, E., \& Rawlings, V. (2018). Norms and normalisation: Understanding lesbian, gay, bisexual, transgender and queer youth, suicidality and help-seeking. Culture, Health and Sexuality, 20(2), 156-172. https://doi.org/10.1080/13691058. 2017.1335435

Meckler, G. D., Elliott, M. N., Kanouse, D. E., Beals, K. P., \& Schuster, M. A. (2006). Nondisclosure of sexual orientation to a physician among a sample of gay, lesbian, and bisexual youth. Archives of Pediatrics and Adolescent Medicine, 160(12), 1248-1254. https:// doi.org/10.1001/archpedi.160.12.1248

Meyer, I. H. (2003). Prejudice, social stress, and mental health in lesbian, gay, and bisexual populations: Conceptual issues and 
research evidence. Psychological Bulletin, 129(5), 674-697. https://doi.org/10.1037/0033-2909.129.5.674

Mustanski, B., \& Liu, R. T. (2013). A longitudinal study of predictors of suicide attempts among lesbian, gay, bisexual, and transgender youth. Archives of Sexual Behavior, 42(3), 437-448. https://doi. org/10.1007/s10508-012-0013-9

Nadal, K. L., Rivera, D. P., \& Corpus, M. J. (2010). Sexual orientation and transgender microaggressions in everyday life: Experiences of lesbians, gays, bisexuals, and transgender individuals. In D. W. Sue (Ed.), Microaggressions and marginality: Manifestation, dynamics, and impact, (pp. 217-240). John Wiley \& Sons.

Parra, L. A., Bell, T. S., Benibgui, M., Helm, J. L., \& Hastings, P. D. (2018). The buffering effect of peer support on the links between family rejection and psychosocial adjustment in LGB emerging adults. Journal of Social and Personal Relationships, 35(6), 854871. https://doi.org/10.1177/0265407517699713

Perez-Brumer, A., Day, J. K., Russell, S. T., \& Hatzenbuehler, M. L. (2017). Prevalence and correlates of suicidal ideation among transgender youth in California: Findings from a representative, population-based sample of high school students. Journal of the American Academy of Child and Adolescent Psychiatry, 56(9), 739-746. https://doi.org/10.1016/j.jaac.2017.06.010

Plöderl, M., \& Tremblay, P. (2015). Mental health of sexual minorities. A systematic review. International Review of Psychiatry, 27(5), 367-385. https://doi.org/10.3109/09540261.2015.1083949

Poštuvan, V., Podlogar, T., Zadravec Šedivy, N., \& De Leo, D. (2019). Suicidal behaviour among sexual-minority youth: A review of the role of acceptance and support. The Lancet Child and Adolescent Health, 3(3), 190-198. https://doi.org/10.1016/S2352-4642(18) 30400-0

Radboudumc. (n.d.). Transgenderzorg. Retrieved 30 June 2021, from https://www.radboudumc.nl/expertisecentra/geslacht-en-gender/ waarvoor-kunt-u-bij-ons-terecht/transgenderzorg

Rossman, K., Salamanca, P., \& Macapagal, K. (2017). A qualitative study examining young adults' experiences of disclosure and nondisclosure of LGBTQ identity to health care providers. Journal of Homosexuality, 64(10), 1390-1410. https://doi.org/10.1080/ 00918369.2017.1321379

Ryan, C., Huebner, D., Diaz, R. M., \& Sanchez, J. (2009). Family rejection as a predictor of negative health outcomes in White and Latino lesbian, gay, and bisexual young adults. Pediatrics, 123(1), 346-352. https://doi.org/10.1542/peds.2007-3524

Ryan, C., Russell, S. T., Huebner, D., Diaz, R., \& Sanchez, J. (2010). Family acceptance in adolescence and the health of LGBT young adults. Journal of Child and Adolescent Psychiatric Nursing, 23(4), 205-213. https://doi.org/10.1111/j.1744-6171.2010. 00246.x

Schimmel-Bristow, A., Haley, S. G., Crouch, J. M., Evans, Y. N., Ahrens, K. R., Mccarty, C. A., \& Inwards-breland, D. J. (2018). Youth and caregiver experiences of gender identity transition : A qualitative study. Psychology of Sexual Orientation and Gender Diversity, 5(2), 273-281. https://doi.org/10.1037/sgd0000269

Sherriff, N. S., Hamilton, W. E., Wigmore, S., \& Giambrone, B. L. B. (2011). "What do you say to them?" Investigating and supporting the needs of lesbian, gay, bisexual, trans, and questioning (LGBTQ) young people. Journal of Community Psychology, 39(8), 939-955. https://doi.org/10.1002/jcop.20479

Shilo, G., \& Savaya, R. (2011). Effects of family and friend support on LGB youths' mental health and sexual orientation milestones. Family Relations, 60(3), 318-330. https://doi.org/10.1111/j.17413729.2011.00648.x

Simons, L., Schrager, S. M., Clark, L. F., Belzer, M., \& Olson, J. (2013). Parental support and mental health among transgender adolescents. Journal of Adolescent Health, 53(6), 791-793. https://doi.org/10.1016/j.jadohealth.2013.07.019

Snyder, B. K., Burack, G. D., \& Petrova, A. (2017). LGBTQ youth's perceptions of primary care. Clinical Pediatrics, 56(5), 443-450. https://doi.org/10.1177/0009922816673306

Taliaferro, L. A., \& Muehlenkamp, J. J. (2017). Nonsuicidal self-injury and suicidality among sexual minority youth: Risk factors and protective connectedness factors. Academic Pediatrics, 17(7), 715-722. https://doi.org/10.1016/j.acap.2016.11.002

Testa, R. J., Habarth, J., Peta, J., Balsam, K., \& Bockting, W. (2015). Development of the gender minority stress and resilience measure. Psychology of Sexual Orientation and Gender Diversity, 2(1), 65-77. https://doi.org/10.1037/sgd0000081

Torok, M., Calear, A. L., Smart, A., Nicolopoulos, A., \& Wong, Q. (2019). Preventing adolescent suicide: A systematic review of the effectiveness and change mechanisms of suicide prevention gatekeeping training programs for teachers and parents. Journal of Adolescence, 73, 100-112. https://doi.org/10.1016/j.adolescence. 2019.04.005

Van Bergen, D. D., Bos, H. M. W., Van Lisdonk, J., Keuzenkamp, S., \& Sandfort, T. G. M. (2013). Victimization and suicidality among Dutch lesbian, gay, and bisexual youths. American Journal of Public Health, 103(1), 70-72. https://doi.org/10.2105/AJPH. 2012.300797

Van Spijker, B. A. J., Batterham, P. J., Calear, A. L., Farrer, L., Christensen, H., Reynolds, J., \& Kerkhof, A. J. F. M. (2014). The Suicidal Ideation Attributes Scale (SIDAS): Community-based validation study of a new scale for the measurement of suicidal ideation. Suicide and Life-Threatening Behavior, 44(4), 408-419. https://doi.org/10.1111/ sltb. 12084

VUmc. (n.d.). Kennis- en zorgcentrum genderdysforie. Retrieved 30 June 2021, from https://www.vumc.nl/zorg/expertisecentraen-specialismen/kennis-en-zorgcentrum-genderdysforie.htm

Watson, R. J., Grossman, A. H., \& Russell, S. T. (2019). Sources of social support and mental health among LGB youth. Youth and Society, 51(1), 30-48. https://doi.org/10.1177/0044118X16660110

Zelin, N. S., Encandela, J., Van Deusen, T., Fenick, A. M., Qin, L., \& Talwalkar, J. S. (2019). Pediatric residents' beliefs and behaviors about health care for sexual and gender minority youth. Clinical Pediatrics, 58(13), 1415-1422. https://doi.org/10.1177/00099 22819851264

Publisher's Note Springer Nature remains neutral with regard to jurisdictional claims in published maps and institutional affiliations. 